\title{
Microwave-Assisted and Green Fabrication of Carbon Quantum Dots from Viburnum opulus for Potential Bioimaging Applications +
}

\author{
Serkan Dayan \\ Drug Application and Research Center (ERFARMA), Erciyes University, 38280 Kayseri, Turkey; \\ serkandayan@erciyes.edu.tr; Tel.: +90-506-277-21-75 \\ + Presented at the 3rd International conference on Natural Products for Cancer Prevention and Therapy, \\ Kayseri, Turkey, 18-20 December 2019.
}

Published: 25 December 2019

Keywords: carbon quantum dots; green synthesis; Viburnum opulus; bio-applications

Early diagnosis is very strategic for today's diseases such as cancer and infectious diseases. Most of the mortality in these diseases has not been diagnosed early and the mortality rates decrease significantly in early diagnosed cases. Carbon quantum dots (C-dots), which are fluorescent materials used in early diagnosis methods, are both novel and promising materials. The carbon quantum dots have proved their usefulness in bio-applications with this feature. Herein, we reported that a step facile-green microwave-assisted hydrothermal fabrication of C-dots was carried out from Viburnum opulus as a green substrate (Figure 1). The characterization of the fabricated C-dots from Viburnum opulus was accomplished by Fourier transform infrared spectroscopy (FT-IR), UV-vis spectrophotometer, and field-emission scanning electron microscope (FE-SEM). The carbon quantum dots have multifunctional properties that can be found in many areas. For example, they are important materials that can be used in high-performance nanoprobes, bio-imaging applications, molecule labeling applications, labeling and imaging techniques in cancer cells, and as contrast agents.

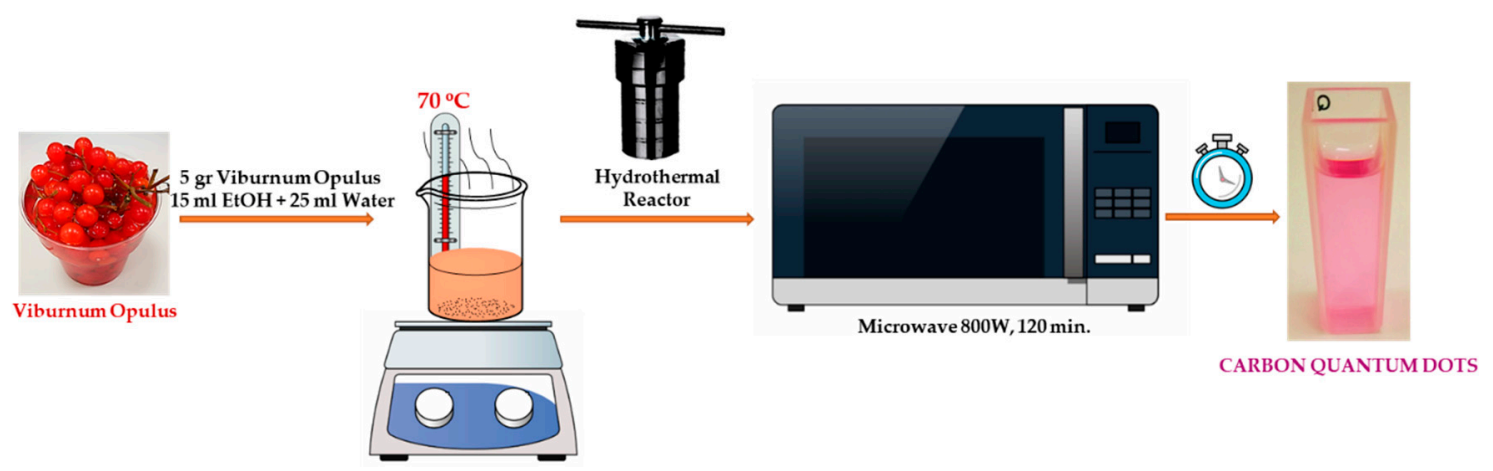

Figure 1. Fabrication of carbon quantum dots (C-dots) from Viburnum Opulus.

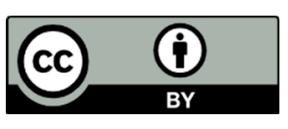

(C) 2019 by the authors. Licensee MDPI, Basel, Switzerland. This article is an open access article distributed under the terms and conditions of the Creative Commons Attribution (CC BY) license (http://creativecommons.org/licenses/by/4.0/). 